\title{
SEMIOTICS IN INDIGENOUS DANCE PERFORMANCES: EKELEKE DANCE OF EKWE PEOPLE OF NIGERIA AS PARADIGM
}

\author{
Nicholas Chielotam Akas \& Martha Chidimma Egenti \\ http://dx.doi.org/10.4314/og.v12i s1.14
}

\begin{abstract}
The potency of the use of semiotics in dance is no longer a strange knowledge. Scholarly interpretations on the use of semiotics, in our indigenous dances, present semiotic movement in dance as a reflective pointer in upholding the communal essence of any given society both in myth, customs and legendary experiences. The problematic questions in this paper are as follows: of what essence is the use of semiotics in Ekeleke dance? Where did the use of semiotic movement in the dance (Ekeleke) emerge from? And, what is the interpretative and communicative essence of the use of semiotic movement in dance? In order to answer these hydra-headed questions, this paper focuses on the positive use of semiotics in Ekeleke dance and its communicative ability on the choreographer, the dancers and the audience. To achieve the interpretative essence needed in this paper, the ethnographic framework was used as content analysis on the dance Ekeleke. Our findings reveal the originality, sacredness and cultural sustainability portrayed in the dance through the use of communicative semiotic movements. In conclusion, the communicative essence of semiotics in Ekeleke dance performance presents Ekwe people; situated in Isu local government Area of Imo State, as a people of traceable source of origin and not as mere cultural entertainers.
\end{abstract}

\section{Introduction}

Indigenous dance as an art generates impulse and signal that are creatively channeled to the audience through the manipulation of the human body. Indigenous dance is dynamic because its kinetic code varies based on quality and design of body movements. Ikike Ufford states that: Indigenous is not arbitrarily created, it goes through 
Akas \& Egenti: Semiotics in indigenous dance performances...

different phases such as the gathering of movement, developing them and designing the final structure. (105)

Indigenous dance to an African is a way of life, a true representation of a people's existence expressed through movement. Indigenous dance is also an integral part of African culture because movements play vital roles in communication. Samartha Charlmers states that;

Indigenous dance is an expressionistic tool utilized to capture, express, embody and formulate any given representation of our transitional indigenous culture. It is used in its form, accompanied by a semiotic song and music, to entertain and educate the indigenes. (1)

The indigenous dance symbolizes social structure and traditional values of the people where it exists. It assists indigenes to praise, criticize as well as work with each other. Alphonse Tierous-Doople opines that;

Indigenous dance in Africa is used as a functional tool for expression and has and is used for a variety of reasons. It is used in ritualistic purposes, aesthetic enjoyment, courtship, personal communication and cultural continuity cum sustainability. (1)

The history and traditions of indigenous dance and movement focus on communication. Indigenous dance is not a natural object but something made or transformed by man for his cultural sustainability, mobilization and sensitization. LizeKriel states that;

Indigenous dance is not a luxury... it is part of each person's physical, emotional, intellectual and cultural growth. It is a language through which indigenes can share each other's pains and accomplishment. (6) 
Indigenous dance is an essential communicative social event, which not only accommodates, but encourages and appreciates participation by spectators, and is elastic enough to expand or contract in time according to the quality of the performance and the interest of the audience. The cultural influence on the indigenous dance defines its technique and style of expression, thereby strengthening the relationship between cultural expression and dance movement as a tool for positive propaganda.

\section{The Cultural Position of Indigenous Dance}

In African societies, indigenous dance serves as a complex diversity of social purposes. Within an indigenous dance tradition, each performance usually has a principal as well as a number of subsidiary purposes which may express or reflect the communal values and social relationships of the people. In order to distinguish the communicative potency of indigenous dance styles, it is necessary to establish the purpose for which each indigenous dance is performed culturally. For instance, at important occasions such as festival, funeral and harvest time, there are always varieties of indigenous dance styles; each of the dance styles portrays the sociocommunicative essence of the situation of the dance being performed at that particular moment. Indigenous dance culturally provides a way for the whole community to meet together to enjoy themselves and see their problems brought to bear before their eyes through dance movements, so that while they are being entertained, a suggestive solution is been proffered for them either to change from bad to good or to remain good. The cultural effectiveness of our indigenous dance has really aided indigenes from same community and those living in the Diaspora to come together and perform their indigenous dances annually in order to uphold and sustain their cultural heritance. Indigenous dance is appreciated culturally as a mere communal performance, but based on its communicative effectiveness when critically looked into, it is an art that has its own right to entertain, inform and educate the indigenes on the uniqueness of their communal life and also remind them of their origin. 
Akas \& Egenti: Semiotics in indigenous dance performances...

\section{The Socio-cultural Semiotic Implication of Indigenous Dance Styles}

Indigenous dance is realized radically in different styles in the multitude of diverse cultures of Africa. The movement patterns in indigenous dance socio-culturally vary greatly from one culture to another, depending on the way in which environmental, historical, and sociological circumstances are been portrayed semiotically in the dance styles or movements. People living on spacious farmlands have different dance movements from those living in swamplands. For those living in savanna area, the ground is solid and their space opens to the far horizon. They place their feet firmly on the ground as they follow their lead dancer performing a simple foot dance pattern at a steady tempo. The people living in the mangrove swamps of the Niger Delta traditionally wrest an uneasy living by fishing creeks and rivers. As they dance, they lean forward from the hips, their torsos almost parallel with the earth as they use a precision of light; rapid foot beats, moving their weight from a level to the toe and to the side of the foot in a variety of rhythmic pattern, picking their way through the swamp. The Kambari of Nigeria continuously bend when entering their low doors and so their indigenous dance posture reflects this habit during any of their performances. The Jukun people sit on low stool with legs crossed or extended, thereby making their knees flexible, which aids them in continuous deep knee bends in their dance movements during performance. It is from the socio-cultural semiotic influence on our indigenous dance style based on its name, styles, form and context that we can understand the reason why communities perform a particular dance style and the religious cum didactic reason behind dances and their movements.

\section{Semiosis, Representation and Interpretation}

The brain's capacity to produce and understand sign is called semiosis, while the knowledge making activity, that is, the capacity that allows all human beings to carryout analysis on signs is known as representation. Representation helps to analyze the use of signs in any context that relates, depicts, portrays or reproduces something perceived, sensed, imagined or felt in some physical form. Charles Peirce in his contextual analysis of representation in its physical 
form uses alphabetical letters to back up and explain his findings more and more. Pierce sees the actual physical forms of a representation as X'representamen'; literally it means that which does the representing. He termed the $\mathrm{Y}$ to which it calls attention. The object of representation and the meaning or meanings that can potentially be extracted from the representation (X and $\mathrm{Y}$ ) are seen as the 'interpretant'. The whole process of deciding the meaning of the representamen is called interpretation. Interpretation is a crucial aspect of the human condition. It aids humans to interpret the sign before them to become something meaningful. With the aid of interpretation, a sign in our cultural performances seizes to be that "thing" and becomes "something" very important in understanding the core existence of every symbol sign in our cultural activities. Perfect use of interpretation skills serves as the conceptual glue that interconnects the body and the mind around the interpreted signs in which they exist holistically. The semiotic interpretative nature of signs with its interconnection to the body, the mind and culture as cited by Danesi (45) can be shown graphically as:

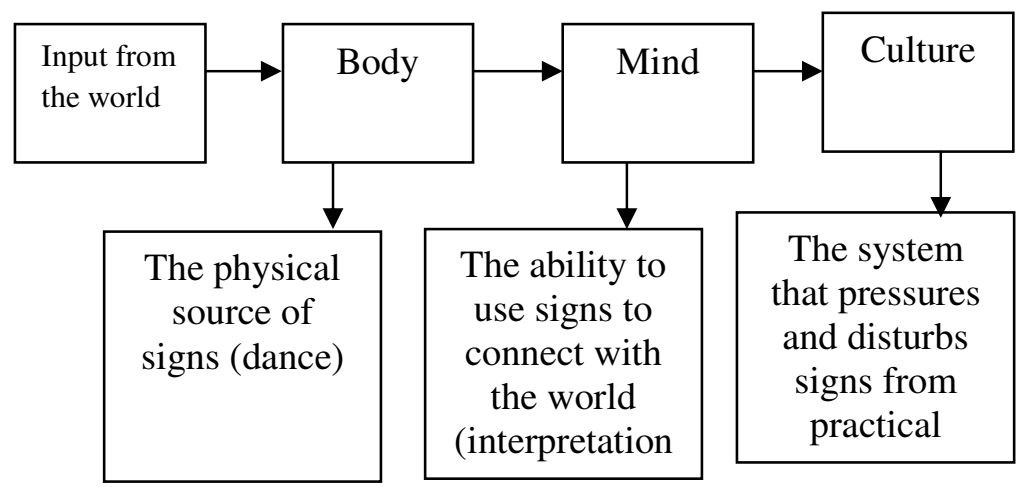

Charles Peirce as cited by Marcel Danesi referred to this diagram based on three dimensions as 'firstness, secondness and thirdness'.

A sign starts out as a sensory structure, that is, as that which has been made to simulate an objective term of its sensory properties (firstness). It is then used by the sign-user to establish a connection 
Akas \& Egenti: Semiotics in indigenous dance performances...

to the object, even if the actual object is not present for the senses to perceive (secondness), and finally the sign itself becomes a source of knowledge about the world, once it enters the world of culture and distributed for usage (thirdness). Cultures are essentially "signpreserving" systems that distribute signs to people for various kinds of practical purpose .Danesi asserts that "the cultural signs of any community tell more about the community that owns it and also differentiates them from other people's culture (276).

Furthermore, Danesi distinguishes between social, mythic, knowledge and narrative codes used on interpretative implementations. Social codes are those that can be used to interpret social communication and interaction. Mythic codes are those sign systems that enable knowledge such as mathematics, science and philosophy to be represented and communicated, while narrative code is a story that portrays or represents human events as perceived in a particular timeframe. Hence, a sign can be interpreted in many ways depending on the codes used. It is the communicative essence of codes that stands as a frame of reference in interpretation of dance movements. The choreographer communicates positively through the dancer's body using symbolic sign movements that express his/her feelings, emotion and ideologies before and after the creation of the dance signs.

\section{Body Language}

Body language is the general term used to indicate communication by means of gestures, postures and other variety and unknowing body signals and signs. It also includes grooming habits, hair and clothing styles and practices such as tattooing and body piercing. Body language communicates unspoken information about people's identity, relationships and thoughts, as well as moods, motivation and attitudes. Danesi opines that;

The meanings of body language vary among different cultures. It is the communicative potency of body language that gives a look and feel to a conversation remembered long after spoken words fade away. (247) 
Body language with the aid of non-verbal signs communicates peoples' innermost intentions. The interpretative potency placed on each body language takes its communicative essence closer to the people. At this point, not anyhow body movement can be seen as body language, rather those body languages that work on these guiding metaphors such as:
A. To investigate any existing issues.
B. To understand the cause to the existing issues
C. To identify person or persons behind the issues
D. To proffer solution on how to put an end to the existing problems and also how to checkmate those involved in the problems at essential stage.

Body language based on the above mentioned points becomes a positive tool for positive propaganda.

\section{The Types of Documenting Framework Used in Sustaining the Semiotic - Communicative Potency in Indigenous Dance Styles}

\section{Creation Framework}

The creative process is worthy of documentation and potentially records of dance creation could unveil unique and unpredictable aspects about developing an idea into a finished dance. The documentation of the creation process and its outcome offers essential information for understanding a dance context and also what motivates the choreographer in creating such dance styles or movements.

\section{Presentation Framework}

The presentation framework offers a chance to record the dance performance in an interactive setting, which allows for evidence of audience response and production details that maybe otherwise unreported. The presentation frame is often the context in which choreographers, producers and participants consciously strive to document the dance well. According to Libby Sinigel;

The presentation is usually regarded as the culmination of creative preparation and commitment 
by serious choreographers and dance companies to motivate the participants to take steps to document the communicative semiotic dance movement which serves a reflective point in communal moral sensitization. (28)

The presentation framework helps to expose the creative work of the choreographer before a live audience to arouse their interpretative understanding cum constructive criticism beyond aesthetic appeal. The presentation framework takes the indigenous dance much closer to the people that own it, which make them to appreciate and cherish the dance more.

\section{Transmission Framework}

This framework is typical of classical or traditional dance forms, whether western or non-western. When the dances are not intended to be seen or practiced outside the community in which they are located, transmission framework becomes paramount, thereby restricting non-indigenes in the existing dance from having access to it, while the indigenes maintain and sustain its originality by being part of the dance. Some of the dances handed down through the transmission framework have been codified in movement and style by communities to portray its uniqueness from other cultures when they are placed side by side.

\section{Ethnographic Framework}

Here the researchers are allowed to document on any existing dance. The ethnographers watch the dance to observe and interpret it beyond mere aesthetics. Libby states that;

...while the ethnographer may use tools to reward the dance or event, the purpose of the recording would not be to replicate or re-stage the performance, but to transmit the knowledge accurately within a cultural, social and educational context of the dance. (29) 
The sole of ethnographic framework is to perform interpretative look at the communicative potency of dance styles based on its sociological essence beyond mere aesthetically combined dance movements by the choreographer

\section{Dance as a Symbolic Language}

Symbols are used to portray an idea, message, law or rule or to identify certain objects, facilities or services without using language. In daily activities asides dance, man is always faced with communicative symbols such as; road signs, safety signs and symbols for certain brand products in adverts. All these symbols in man's daily activities are all geared towards guiding his movement from not making unnecessary mistakes, avoiding unforeseen accidents and directing him when, where and how to get what he wants at any given time. But in dance, the use of symbol serves as a language through the body of the dancers who dance for various reasons, mostly to have fun and to release energy. Dance to celebrate birth, weddings and change of seasons, have meaning and do not exist in vacuum. Cass $\mathbf{J}$ states that;

Dancing assists people to express their emotions, desires and ideas. Many people love dancing because it satisfies an emotional or spiritual need and gives them a sense of inner fulfillment. (2)

Dance is used to communicate ideas, information, beliefs, thoughts and emotions. It can transcend language and culture because it uses a universal tool which is human body. The use of useful and meaningful gesture in dance makes it a symbolic language tool for communication. The level of the symbolic language exhibit in dance cuts across barriers of language and culture, thereby making it a universal tool for communication irrespective of tribes, religion, tradition and profession. Roxy Levy maintains that;

Choreographers/producers use symbolism to communicate with the audience. They usually have a certain story or idea in mind that they want to 
Akas \& Egenti: Semiotics in indigenous dance performances...

portray. This is what is called the "intent" of the dance worlds. (5)

The choreographer will always try to achieve the intent in dance through the dance movements of the dancer and also through the music, costumes, make-up, set lights and any other effects. These entire elements when carefully put together in dance have a symbolic value to add to the dance. The use of ideal symbolic language in dance both in its style, pattern, formation and contextualization aids the audience perfectly to read, understand and interpret any dance performance. When the audience can understand the communicative potency in the use of symbolic body language, the choreographer has automatically succeeded in entertaining, informing and educating the audience.

\section{An Analysis of Ekeleke Dance of Ekwe Umundugba in Imo State}

\section{Origin of the Dance}

The origin of Ekeleke dance is very symbolic in Ekwe Umundugba, Imo State. According to Chief Stephen Akas in an interview, 'The dance is believed to have emerged from women at the early stage of the performance before it was adopted by the men in the community. The women in their aesthetic dressing performed the dance in the village during special occasions and festivals". It is also believed that the beautiful nature of the dancer's costume while performing the dance tells more of the dancer's state of mind, emotions and mood while on stage. In line with this, Chief Stephen Akas in an interview said that so much emphasis is placed on each dancer's costume, make-up, props and carriage while performing on stage'. This is why the dance is called Ekeleke meaning 'Dressing'. On the day of performance, the audience would come and watch the best dressed dancer and her carriage on stage. In doing so the communicative essence of dancers' movements is de-emphasized and so much attention is paid to their costumes. That is why the dancers on their part place more emphasis on beautifying themselves as females in all forms and manners in order to achieve the required pictorial aesthetics and de-emphasize the potency of the dance movement. At a point, according Chief Keneth Onyeama in an 
interview, men from three communities; Umudidi, Ibeoma and Uburuekwu decided to take the dance beyond its mere aesthetic level, adopting it from the women and re-modifying it to suit both the social, political and religious situations of the community.

The originality of the Ekeleke dance is not in dispute but the adapted form had elements like spectacle, vigorous dance movement, costumes and dance props added to it. The men from the communities that adapted this dance also added sacred items which are intended to make the adapted dance more masculine, energetic, communicative and spectacular.

\section{Initiation ceremony}

Ekeleke dance performance is supposedly a unique dance when compared to other dances in Ekwe community. According to Chief Onyeama, this is because it is strictly for full initiates in the community, that is, membership is strictly for people who have come of age and can keep the rules and regulations guiding the dance'. It is a dance believed to be for men who are ready to defend and uphold the customs, traditions and moral values of Ekwe community. According to Barr. Dr K.Ogueri in an interview, 'before the initiation ceremony into Ekeleke dance, people who have declared interest to become members would visit the house of the lead dancer called Onyeisi Ekeleke, to be acquainted with the rules and regulations guiding the performance. Among the rules are as follows; the initiates are expected to be freeborn members of the community. In Ekwe community, the ideology of being freeborn is for one not to be an outcast, because it is forbidden for an outcast to be initiated into the dance. Based on this, individuals to be initiated are referred to as free born people and will always receive blessings from their ancestors, who are believed to be partakers in the dance. The blessings which are metaphorical in nature always come in the form of favours, bountiful harvests and breakthroughs.

This dance is not an everyday performance rather it is done in June which is the period of the planting season in the community. It is of their belief semiotically that with the use of the dance, their ancestral fathers would give them a bountiful harvest. 
The costumes for the dance are usually highly fortified with charms and other protective items for they are meant for the initiates only and it is the general belief that once a non- initiate comes into contact with the costume, he would lose consciousness for six months before series of purification rites would be performed for him to regain his consciousness.

Plate 1: Ekeleke dance costume

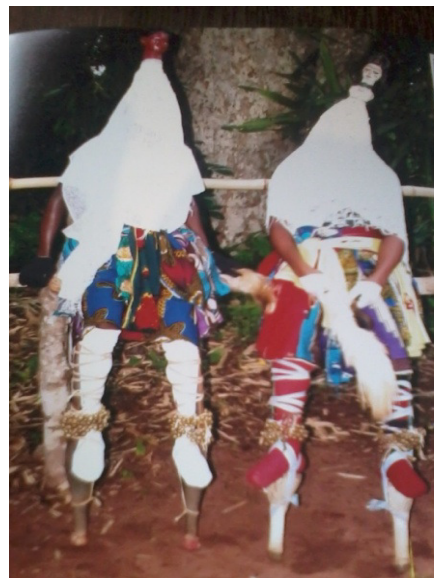

The dance performance and its steps can only be taught by the Onyeisi Ekeleke who is the lead dancer and head of the performers. He is believed to be a descendant from the lineage of the Ekeleke lead dancers. The inspiration to choreograph the Ekeleke dance is believed to come from the gods and is bestowed on this lineage of dancers.

When the rules and regulation guiding the dance are fully completed and grasped by the intending initiates, a date is then set aside for the final initiation process. The ideal age for the initiation is 16 years and above. This is because in Ekwe community, it is believed that youths of this age are still young, obedient, respectful and ready to learn and uphold their customs and traditions. Two things are very symbolic during the initiations which are; the time 8pm and the month which is June-July. June - July in Ekwe community is the planting season, the youths who are supposed to be initiated return home and help their parents in planting at their various farms during the planting season. By so doing, significantly, the youths are tested on their sense of hard work, obedience and the 
desire to provide and help their parents especially in their old age when their strength will fail them. After the planting season, the next thing is the harvesting season. It is what was planted during the planting season that would be harvested and used for the initiation. The initiates would be informed about the necessary food items to bring during their initiation ceremony. The necessary items to be provided on the day of initiation include rice, akpu 'cassava', ukwa 'bread fruit', ten gallons of palm wine, a big he-goat, bottles of beer, kolanuts and hard drinks. The need for these food items is to present the initiates to the gods for cleansing and purification and to invite both the living and the dead for a great festivity after the initiation. It is significant to note that it is during the initiation that the gods dine and wine with the living. Another symbolic thing during the initiation is the time $8 \mathrm{pm}$. According to Chief Sir N.O. Akas (a historian) in an interview, "the reason for the time is for their forefathers that danced Ekeleke while they were alive to witness the initiation ceremony'. The ancestral spirits, as it is believed, symbolically conduct initiation of the dead ones who were not opportuned to be initiated when they were alive. The initiates are expected to arrive 30 minutes before the ideal time. The reason for 30 minutes before the time is to give the ancestral spirits who are initiates too, time to be fully prepared for the initiation. The initiates arrive in their simple and every day wear. In their various bags is their dance costume called Akwa Egwu Ekeleke 'Ekeleke dance cloth'. The initiates, during the process of their initiation are informed that the same process is ongoing in the ancestral land for those who were not opportuned to be initiated in their life time. This apparently is to encourage and ginger them up. At the declaration by the OnyeisiEkeleke that the initiation process has been completed, drummers begin beating their drums amidst jubilation as the initiates are made to dance as an expression of their joy as Ekeleke dance initiates. Those serving food commence serving immediately. 
Plate 2: An initiate before initiation and after initiation

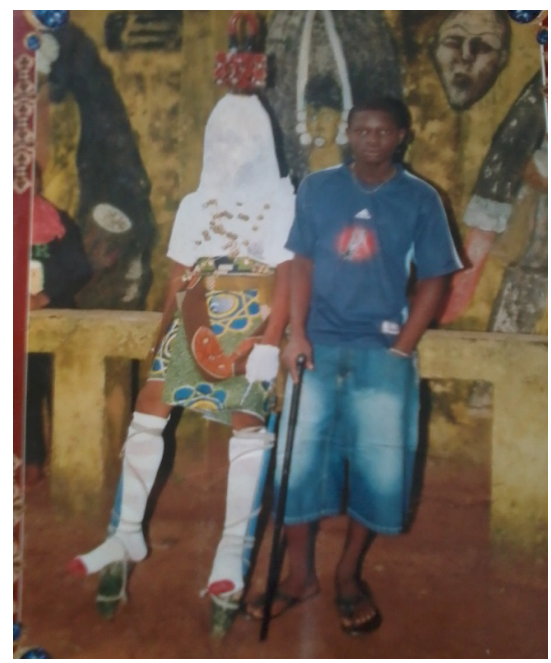

\section{The Orchestra}

According to $\mathrm{Mr}$ Onyeama (Lead Dancer) in an interview, the drummers of this great and ageless dance performance are men between the ages of 40-55 years. The reason for using the men between this age limit as drummers according to Mr Onyeama is because they are seen as custodians in drumming the beat of the dance performance. Their drumming style is beyond mere drumming of art for art sake, rather it communicates the various moods, feelings, temperaments of the dancers as they exhibit their steps and situation of things at the point the Ekeleke dancers are on stage. The essential instruments required for performance are three Ekwe wooden gong which are Ekwe okpooku, Ekwe Nkwado and Ekwe Omume. These wooden gongs (Ekwe) have communicative potentials. A description of the three Ekwe will be attempted

\section{Ekwe Okpo Oku (The Cue Instrument)}

This particular type of Ekwe is very symbolic in the dance performance. It is symbolic in the sense that it is used to invite the Ekeleke dancers to get ready for the performance. This is not just ordinary summon, but significantly, it reminds the dancers that they are about to perform before a live audience and their unseen ancestral fathers. Hence they should give in their best as dancers and 
forget about anything that will disturb them or make them not to perform well. According to Mr Onyeama, 'the drummer in charge of Ekwe Okpo Oku beats the Ekwe continuously, but on a very slow beat. This continuous slow beating of Ekwe Okpo Oku helps the dancers get ready for the actual dance. Also, it reminds them that they are performers and they must do everything possible to entertain their audience who have travelled from far and near to watch the performance', On hearing this particular Ekwe Okpo Oku based the Sense Making Theory, the Ekeleke dancers motivate themselves for the great task ahead and remind the audience that they should forget all their worries and come out in their numbers to watch this great performance.

\section{Ekwe Nkwado (The Motivating Instrument)}

This is another of the wooden gongs. The fast rhythmic tone of the Ekwe Nkwado is able to put the dancer in the right frame of mind and prepare them psychologically for the dance performance. It is of belief in Ekwe community according to Mr Onyeama, that while performing the Ekeleke dance movements, the dancer is automatically transformed spiritually to the ancestral world to present his needs to them through a Sense Making Trace- Semiotic Movement. The use of this instrument helps the dancers to add individual dance steps freely and in their chosen styles. This is where each dancer is allowed to introduce personal dance steps and be creative while still communicating with his dance movement to the audience. The audience on their part expresses their joy by dancing to the beats of the Ekeleke dance performance. The expression of such feelings is achieved by their response to the beat of Ekwe Nkwado in dance movements as they also try to initiate dancers. The audience believes this process as purifying. There is a presupposed belief that high point of the dance performance connotes the point when the ancestors come as visitors to the performance and the ambiance changes. At this point, people are abhorred from shouting or pointing at the dancers.

\section{Ekwe Omume (The Action Instrument)}

This instrument aids the dancers to display their individual abilities in Ekeleke dance movement. It is at this point that individual dancers 
show how skilled they are in performing the dance. The rhythmic sound of the instrument is usually fast and symbolically portrays high point of the dance where men and ancestors meet. No other person except initiates is allowed to participate during the performance, the dancers at this point (through the Sense Making Theory) dance to entertain the audience and to show skills and the ability to dance comfortably on top of a well carved stick. This ability of the individual to dance on top of the carved stick on a very high speed without falling from it makes him a master of the art and also shows high level of professionalism exhibited by the dancers as they perform on stilts. Onyeama in an interview states that; "Good skilled dance movement from the dancer earns him a lot of nicknames such as; Onyenweegwu 'owner of dance himself', Nwokeike 'a strong man', and ukwuagu which means 'the lion','. The drummers are decorated with palm fronds which portray them as initiates and custodians of the ageless Ekeleke drums. They are highly skilled in maintaining the cues of the three Ekwe drums. Till date, Ekwe as an instrument in Ekeleke remains an indispensable tool in the dance.

\section{The Audience}

The audience is an essential element that makes the Ekeleke dance thick, hence they are not restricted from seeing the performance. The presence of the audience is a big plus to the Ekeleke performance as their shouts of joy act as a boot to the dancers.

The native indigenes and non-natives who constitute the audience consciously or unconsciously make a theatre-in-the round while watching the performance. Their circular movements during the performance serve as the wall of the theatre, while centre of the arena serves as the performing stage for the Ekeleke dancers. Members of audience are allowed to take pictures of various performances, but as non-initiates, they are not allowed to be inside the centre where the performance is taking place. The reason for not allowing them to go close is because the initiates are fortified with charms, so close contact with the audience might affect their charms .The aesthetic essence of the dance both in its style, form, costumes, performing space, dancers and drummers has succeeded in drawing more and more people to the performance annually. 
Plate 3: The audience watching Ekeleke dance performance (onyeama 2012)

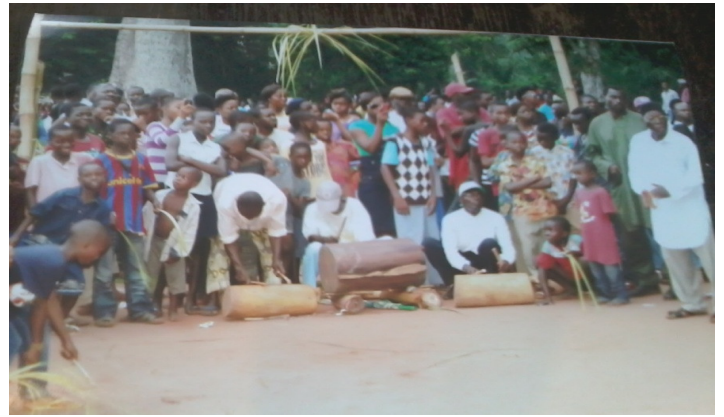

Plate 4: The ageless Drummers of Ekeleke dance and the symbolic ekwe(Onyeama, 2012)

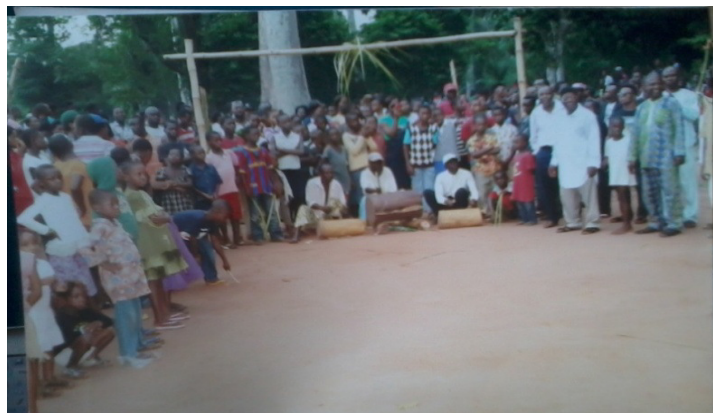

Plate 5: The performance arena, full initiates and the Ekeleke dancer

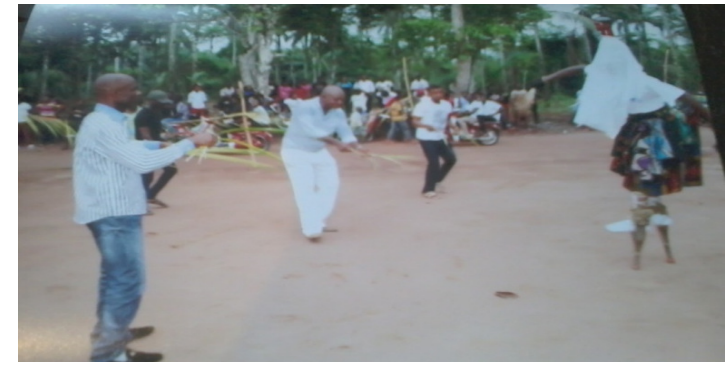

\section{Ekeleke Dance Movements}

The communicative and symbolic idea about dance through Sense Making Theory depends so much on the leg movements of dancers on stage when critically examined. The dancers known as Ekeleke dancers use their various leg movements to interpret the social 
problems of the time. The dancers are seen as the communicating link between the ruling class and the ruled. The dance movements when interpreted semiotically can portray or pass across three symbolic messages to the audience if being watched beyond mere aesthetics. The three levels of the semiotics passed across by the dancers through their dance movements are as follows: when will it be better, it is already getting better and at last it is time to celebrate.

\section{When will it be Better (Olee mgbe $Q$ ga adị mma)}

The above is a dance movement. The dance movement here is always in a very slow beat as if the dancer is weak, worried, confused or not in the mood of dancing at all. The dancer depicts these various states of uncertainty in his dance using a dull coloured costume, holds a black horse tail, female-like carved face as props and with a small hand fan. This hand fan is symbolic according to Onyeama, it is believed that the dancer would use it to invite the air of the good things of life and hope to the community .It is believed that this hand fan is used to 'call in' hope, favour and all life goodies to be bestowed on the people. The dancer also stands on a carved stick which is the tool for the dance, while he puts on dull socks. The dull socks portray symbolically the different stages of unseen circumstance one passes through in life. It further portrays a symbolic and communicative essence when interpreted the struggle of some indigenes to survive in their various sources of endeavors and also the cries of parents on Almighty God to provide for their children and great grandchildren. All these are interpreted in the dancer's slow movement which he sustains for a long time and leaves, before another dancer who will pass another message will come into the arena with his dance movement semiotically interpreted too. 
Plate 6: Olee mgbe o ga aka mma (When will it be better?)

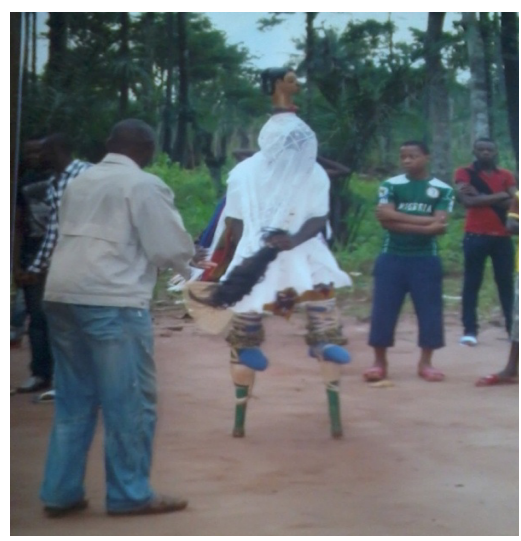

Plate 7: O kawala mma. (It is better!)

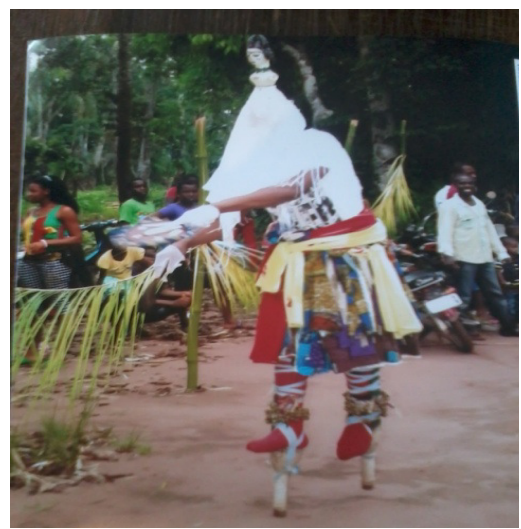

\section{It is Better (O kawala mma)}

This dance movement usually has a fast note and the spectators put on smiling faces unlike in "when will it be better". The dance movement of the dancer here reassures the indigenes that no matter how bad the situation of things are to them, they should always believe in God.

\section{At last it is time to celebrate (Ugbu a buzị oge inwe anụrị)}

The above dance style semiotically portrays the celebration mood of the indigenes after harvesting their bountiful farm produce. It is believed that Almighty God really cared for them by giving them a 
Akas \& Egenti: Semiotics in indigenous dance performances...

bountiful harvest and in order to show appreciation during the period of this dance celebration, there is always much to drink and merry. The dance movement is of a free style where individual dancers make vigorous movements based on his strength and ability to follow the fast tempo of drums. The dancers dance to thank God and plead with him to continue His blessing.

Plate 8: Ugbu a buzi oge inwe anuri (This is now time to be joyous)

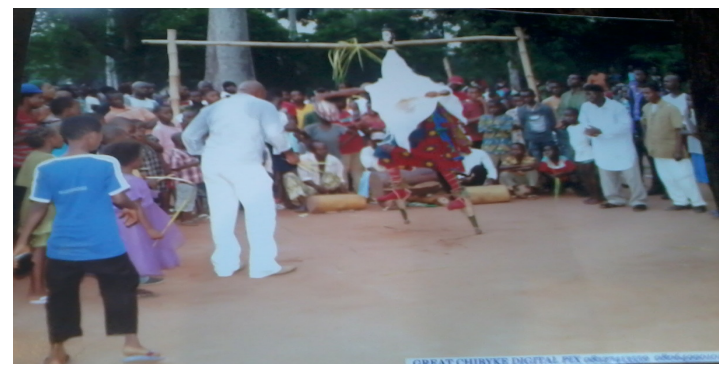

\section{Costume}

The dance costume in Ekeleke is very symbolic. It is symbolic in the sense that it portrays the individual state of mind during the festival. Onyeama observed that; 'It is of belief that through the dance costume based on its symbolic colour 'white', the dancers are pure in thought, action and words. Throughout the dance performance based on the communicative potency of the colour white, the dancers are meant to uphold the truth and nothing but the truth.

Plate 9: Ekeleke dance costume

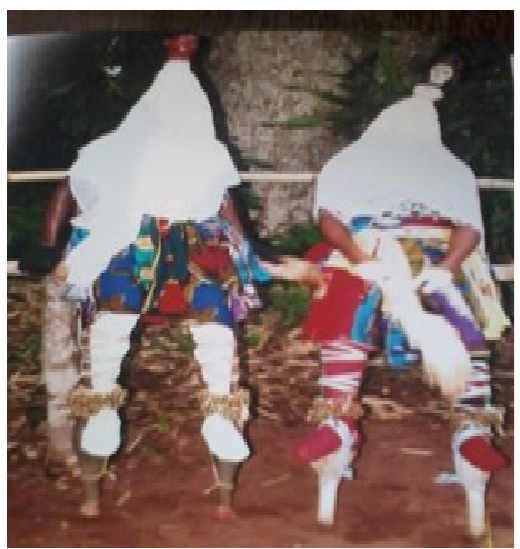




\section{Conclusion}

The scholarly interpretation placed on the use of semiotic in Ekeleke dance performance in Ekwe community has really aided through this paper in bringing out the communicative potency of the dance as an interrogative tool in seeking the truth. Based on this, the use of semiotics in the dance performance is to project the socioenvironmental status of Ekwe community that gave rise to the dance, thereby making the effective essence of semiotics at this point not only as mere aesthetics but a serious and important reflective mirror for the indigenes to change from bad to good and also see their indigenous performance as a watchdog. In conclusion, the use of semiotics in indigenous dance performance gives a subjective interpretation on the emergent of the dance movement based on its importance to the community and their mythology. 
Akas \& Egenti: Semiotics in indigenous dance performances...

\section{References}

Alphonse TrerorDuople. Essence of Semiotics.Ghana. University Press. 2004

Barr. Dr. K. Ogueri. Personal Interview, Umundugba Community Town Hall. $\left(5^{\text {th }}\right.$ September, 2014)

Cass John. Music and Trance. Indiana: Indiana University Press. 2001

Chief Kenneth Onyeama. Personal Interview, Community Secondary School, Erim, (5 $5^{\text {th }}$ August 2014)

Chief Sir N. O. Akas. Personal Interview, B22 Road, McloseFestac Town Lagos $\left(8^{\text {th }}\right.$ November, 2014)

Chief Stephen Akas. Personal Interview, Erim Central Market, Erim Village ( $3^{\text {rd }}$ July 2014)

IkikeUfford. The Arts of Dance: A critical Appraisal of concepts and movement, Journal of Theatre and media Studies, (ed) Charles E. Nwadigwe. Enugu: Academic Printing Press. 2011.

KirelLize. Cultural Semiotics. Indiana: Indiana University Press. 2004.

Libby Sinigel. Social Semiotics. London: University Press, 2000.

Marcel Danesi. Messages and meanings: An Introduction to semiotics. Toronto. Canadian scholar's press. 1994.

Mr. Onyeama. Personal Interview, Ekwe Community Secondary School ( $7^{\text {th }}$ March, 2013)

Pierce Charles. Icons in Music.New York: University Press.2005

Rebecca Stone. A semiotic Analysis of four Designer Clothing Advertisement. London: University of London Press, 2002.

Roxy Levy. Dance Studies, Dance Theory and History Study Guide. South African: University Press. 2007.

Samartha Chalmers. African Dance: The Continuity of Change. Year Book of International Folk Music Council Vol. 5, 165-174, 1973.

Saussure Ferdinand. Course in General Linguistics. New York: McGraw Hill Press. 1959 